\title{
Green synthesis of silver and iron nanoparticles of isolated proanthocyanidin: its characterization, antioxidant, antimicrobial, and cytotoxic activities against COLO320DM and HT29
}

Kiran P. Shejawal ${ }^{1}$, Dheeraj S. Randive ${ }^{1 *}$ (D, Somnath D. Bhinge ${ }^{2}$, Mangesh A. Bhutkar ${ }^{1}$, Ganesh H. Wadkar ${ }^{1}$ and Namdeo R. Jadhav ${ }^{3}$

\begin{abstract}
Background: In the current research, we have developed silver and iron nanoparticles of isolated proanthocynidin (PAC) from grape seed by green synthesis and evaluated for antimicrobial, antioxidant activity and in vitro cytotoxicity against colon cancer cell lines.

Results: One percent solution of isolated proanthocynidin in water was vigorously mixed with $1 \%$ silver nitrate and $1 \%$ ferric chloride solution and kept for $4 \mathrm{~h}$, to yield PACAgNP and PACFeNP. The synthesized nanoparticles were characterized by UV, FTIR, XRD, and SEM analysis and evaluated for antimicrobial potential against selected microbes. Moreover, the synthesized nanoparticles were studied for DPPH assay and in vitro cytotoxicity using colon cancer cell lines COLO320DM and HT29 (MTT, SRB, and Trypan blue assay). UV spectroscopy confirmed the development of nanoparticles. SEM analysis showed that the particles were aggregated in the size range of 50 to $100 \mathrm{~nm}$. Antimicrobial potential was found to be less against Staphylococcus aureus, Pseudomonas aeruginosa, and Escherichia coli, whereas cytotoxicity of PACAgNP and PACFeNP against COLO320DM and HT29 exhibited promising results as compared to the pure PAC. PACAgNP and PACFeNP exhibited $20.83 \pm 0.33 \%$ and $18.06 \pm 0.60 \%$ inhibition, respectively, against DPPH radical, whereas pure PAC showed $16.79 \pm 0.32 \%$ inhibition and standard (ascorbic acid) exhibited $98.73 \pm 0.18 \%$ inhibition of DPPH radical.

Conclusion: The silver and iron nanoparticles were successfully developed by green synthesis method using isolated proanthocynidin which is economical and eco-friendly. The use of metal nanoparticles may open up a new opportunity for anticancer therapies to minimize the toxic effects of available anticancer drugs specifically in targeting specific site.
\end{abstract}

Keywords: Proanthocynidin, Silver and iron nanoparticles, Antioxidant activity, Cytotoxicity, Colorectal cancer, COLO320DM, HT29

\footnotetext{
* Correspondence: randivedheeraj@gmail.com

'Department of Pharmaceutics, Rajarambapu College of Pharmacy, Kasegaon,

Walwa, Sangli, Maharashtra 415404, India

Full list of author information is available at the end of the article
}

\section{Springer Open}

(c) The Author(s). 2020 Open Access This article is licensed under a Creative Commons Attribution 4.0 International License, which permits use, sharing, adaptation, distribution and reproduction in any medium or format, as long as you give appropriate credit to the original author(s) and the source, provide a link to the Creative Commons licence, and indicate if changes were made. The images or other third party material in this article are included in the article's Creative Commons licence, unless indicated otherwise in a credit line to the material. If material is not included in the article's Creative Commons licence and your intended use is not permitted by statutory regulation or exceeds the permitted use, you will need to obtain permission directly from the copyright holder. To view a copy of this licence, visit http://creativecommons.org/licenses/by/4.0/. 


\section{Highlights}

- The present research work is focused on green synthesis of silver and iron nanoparticles of isolated proanthocynidin from grape seed extract.

- This is the first attempt to assess scientifically the anticancer efficacy of the developed metal nanoparticles on in vitro colon cell lines HT29 and COLO320DM.

- The results of the study revealed that developed nanoparticles are having significant cytotoxic activity against colon cancer as compared with pure proanthocynidin (phytoconstituents).

- This is an eco-friendly, economical, easy, and rapid method of development of metal nanoparticles with minimum usage of hazardous chemicals.

- Use of isolated phytoconstituents which are devoid of toxic effects of all other anticancer drugs and better absorption as well as cellular uptake due to nanosize for targeting specific site will be a newer research area.

\section{Background}

A foremost reason of cancer death in men and women is colorectal cancer (CRC), and it affects nearly 1 million people throughout the world every year [1]. It is the third most frequently diagnosed cancer in both men and women. About 103,170 new cases and around 51,700 deaths have been estimated to have occurred in 2012 in the USA. The occurrence of CRC in China is lower than that of western countries, but it has increased in the current years and has become a substantial cancer burden in China, mainly in the more developed areas. Epidemiological literature has shown that the daily consumption of fresh fruits and vegetables is connected with a reduced risk of cancer. The special effects may be moderately attributed to the presence of several polyphenolic compounds, which are known to exhibit antioxidant and free radical-scavenging properties [2].

It is very essential to deliver anticancer drug at the site of action, and the dosage form must exhibit high cell penetration or permeability and drug solubility. Nanoparticles may enter the human body via several routes. The probability of penetration depends on the size and surface properties of particles and on the anatomical structure of the specific sites of the exposure routes [3].

Nanotechnology can be termed as the exploitation of matter through specific chemical and/or physical processes to produce materials with specific properties, which can be utilized in particular applications $[4,5]$. A nanoparticle can be a microscopic particle or material that has at least one dimension less than $100 \mathrm{~nm}$ in size [6-8]. Different bulk materials exhibit sole optical, electrical, thermal, physical, and chemical properties [9], and hence, they find a range of applications in the areas of environment, medicine, chemistry, energy, agriculture, information, communication, consumer goods, and heavy industry $[10,11]$. Recently, there has been a keen interest in the green synthesis of nanoparticles [12].

Owing to the characteristic catalytic and optical properties of the metal nanoparticles as compared to the bulk material, they have fetched greater attention to date in multidisciplinary scientific areas especially in the pharmaceutical, and cosmetic, which position onward growth in commercial interest, and calling for effectual synthesis procedures to match the growing demand of silver, iron, and gold nanoparticles [13].

Ayurvedic and herbal formulations available in the market diverge in quality and therapeutic efficiency owing to the differences in composition of the plant phytoconstituents [14-16]. Advancement in the Ayurvedic herbal medicine has been revolutionized from the showing of phytochemicals and pharmacological activities to elucidating their mechanisms of action and sites of action [17]. Also currently, there is an increased interest in the herbal drugs and remedies for the treatment of chronic diseases [18].

Proanthocyanidins are the naturally available polyphenolic compound(s) which varied in chemical structure, pharmacological action, and characteristics and extensively available in fruits, seeds, vegetables, nuts, flowers, and bark [19].

Grape seed is an abundant source of proanthocyanidin (PACs), which is known to be a powerful inhibitor of aromatase activity; it is an enzyme expressed in higher levels in cancerous than in usual breast tissues [20]. PACs belong to a bigger class of abundant, plant-derived compounds, flavonoids, which offers numerous valuable health effects, largely because of its antioxidant properties [21, 22]. It has been shown to defend against oxidative stress and tobacco-induced DNA damage, and exhibited selective prominent cytotoxicity against some human cancers, including colon, lung, breast, prostate, and gastric carcinomas [23-28].

They are secondary plant metabolites available in many diverse kinds of fruits, vegetables, and plant-based beverages, and also available in cocoa, apple, grapes, tea, and red wine. PAC classes of condensed tannins are oligomers and polymers of $(+)$-catechin and (-)-epicatechin and other related flavonoids, chiefly linked by either B-type (C4 $\rightarrow$ C6 or C8) or A-type linkages ( $22 \rightarrow \mathrm{O} 7)$. Grape seed extract (GSE) falls into the B-type category, and grape seed extract-rich diets have been connected with a reduced risk of chronic cardiac diseases [29] and also a variety of common cancers, including colorectal cancer [30-32].

Proanthocyanins are strong free radical scavengers and are supposed to be contributors to the health benefits of 
fruits and vegetables [33, 34]. Proanthocyanidins obtained from grape seeds have been proven to protect against UV light-induced carcinogenesis, stop immune suppression, enhance interleukin (IL)-12, and decrease IL-10 [35]. Apple PACs have established synergistic effects with lysosomotropic compounds in increasing the anticancer properties targeting human colon cancerderived metastatic cells [36, 37].

An environmentally friendly option is to prepare nanoparticles dependent on three important parameters, namely solvent medium, reducing and stabilizing or capping agent for NPs [38]. Therefore, the present study is important with respect to the development of metal nanoparticles of phytoconstituent specifically for targeting the cancer. It has many advantages like being ecofriendly and cost-effective, and mainly, the isolated phytoconstituents have prominent activity as compared with extract of plants and their parts; moreover, the side effects of the synthetic drugs can be avoided. Further, in vivo animal study of the metal nanoparticle-based formulation is the new area of research.

\section{Methods}

\section{Chemicals}

Proanthocynidin (PAC) was obtained as a gift sample from Influx Healthcare, Mumbai, Maharashtra. All the chemicals used in the study were of analytical grade. Silver nitrate $\left(\mathrm{AgNO}_{3}\right)$ and ferric chloride $\left(\mathrm{FeCl}_{3}\right)$ were purchased from Loba Chem, Kolhapur. Ciprofloxacin was obtained from Okasa Pharmaceutical, Satara. Cell line COLO320DM and HT29 were procured from NCCS, Pune, Maharashtra.

\section{Microorganism used}

The test organisms used in this study were Staphylococcus aureus (ATCC 6538), Pseudomonas aeruginosa, (ATCC 10145), and Escherichia coli (ATCC 8739). The culture was obtained from Yashawantrao Chavan College of Science, Saidapur, Karad (MS), India-415110.

\section{Synthesis of metallic nanoparticles}

\section{Synthesis of proanthocyanidin silver nanoparticles} (PACAgNPs)

PACAgNPs were synthesized using proanthocyanidin solution and $\mathrm{AgNO}_{3}$ solution in accordance with the procedure mentioned by Phull et al. with minor modification [39]. Equal volumes (1:1) of 1\% proanthocyanidin aqueous solution and $1 \%$ silver nitrate solution were incubated at ambient temperature for $2-3 \mathrm{~h}$ to obtain PACAgNPs. Synthesis of PACAgNPs was detected by naked eye with a change of color from dark red to faint brown, which was confirmed by UV spectroscopy. The collected PACAgNPs were centrifuged for $10 \mathrm{~min}$ at 10 ,
$000 \mathrm{rpm}$ and dried in vacuum chamber at $35^{\circ} \mathrm{C}$ shown in Fig. 1.

\section{Synthesis of proanthocyanidin iron nanoparticles (PACFeNPs)}

For the synthesis of ProFeNPs, proanthocyanidin aqueous solution and ferric chloride solution were used in accordance with the procedure mentioned by Raju et al. [40] with minor modification. Ferric chloride (1\%) and proanthocyanidin solution (1\%) were vigorously combined in a ratio of 1:1. The mixture was then placed on an orbital shaker for $24 \mathrm{~h}$ at an ambient temperature to obtain PACFeNPs. The synthesis of PACFeNPs was observed with a color change from dark black to dark brown, which was also confirmed by UV spectroscopy. The collected PACFeNPs were centrifuged for $10 \mathrm{~min}$ at $10,000 \mathrm{rpm}$ and dried in vacuum chamber at $35^{\circ} \mathrm{C}$ shown in Fig. 1.

\section{Characterization of nanoparticles UV-Vis absorbance of PAC, PACAgNP, and PACFeNP}

The development of metal nanoparticles of PACAgNP and PACFeNP by the proanthrocyanidin was recorded periodically using a UV spectrophotometer (Shimadzu). The samples were diluted with $2 \mathrm{~mL}$ of deionized water and measured for UV-Vis spectrum after the formation of nanoparticles that change in color. Deionized water was used as a blank for background correction. All samples were scanned from 200 to $800 \mathrm{~nm}$.

\section{SEM and histogram analysis of PACAgNP and PACFeNP}

Scanning electron microscopy (SEM) is a normally used method of evaluation and morphological analysis of nanoparticles at the nanometer to micrometer scale. Developed PACAgNP and PACFeNP were characterized using a high-resolution scanning electron microscope (Schottky field emission scanning microscope SU5000). The samples were prepared by a simple drop coating of suspended gold solution on to an electric clean glass and allowed the solvent to evaporate, and the samples were dried at room temperature and analyzed in a microscope.

FTIR spectroscopy analysis of PAC, PACAgNP, and PACFeNP To recognize the different biomolecules present in the proanthocynidin and the phytocompounds in $\mathrm{Ag}$ and $\mathrm{Fe}$, nanoparticles after synthesis were analyzed by FTIR (Bruker Alpha Echo ATR). Spectrum was recorded in the range of $400-4000 \mathrm{~cm}^{-1}$.

\section{XRD analysis of PACAgNP and PACFeNP}

The green synthesized silver and iron nanoparticles of PAC were evaluated by XRD analysis using an XRD6000 X-ray diffractometer (Bruker D8 discover) operated 


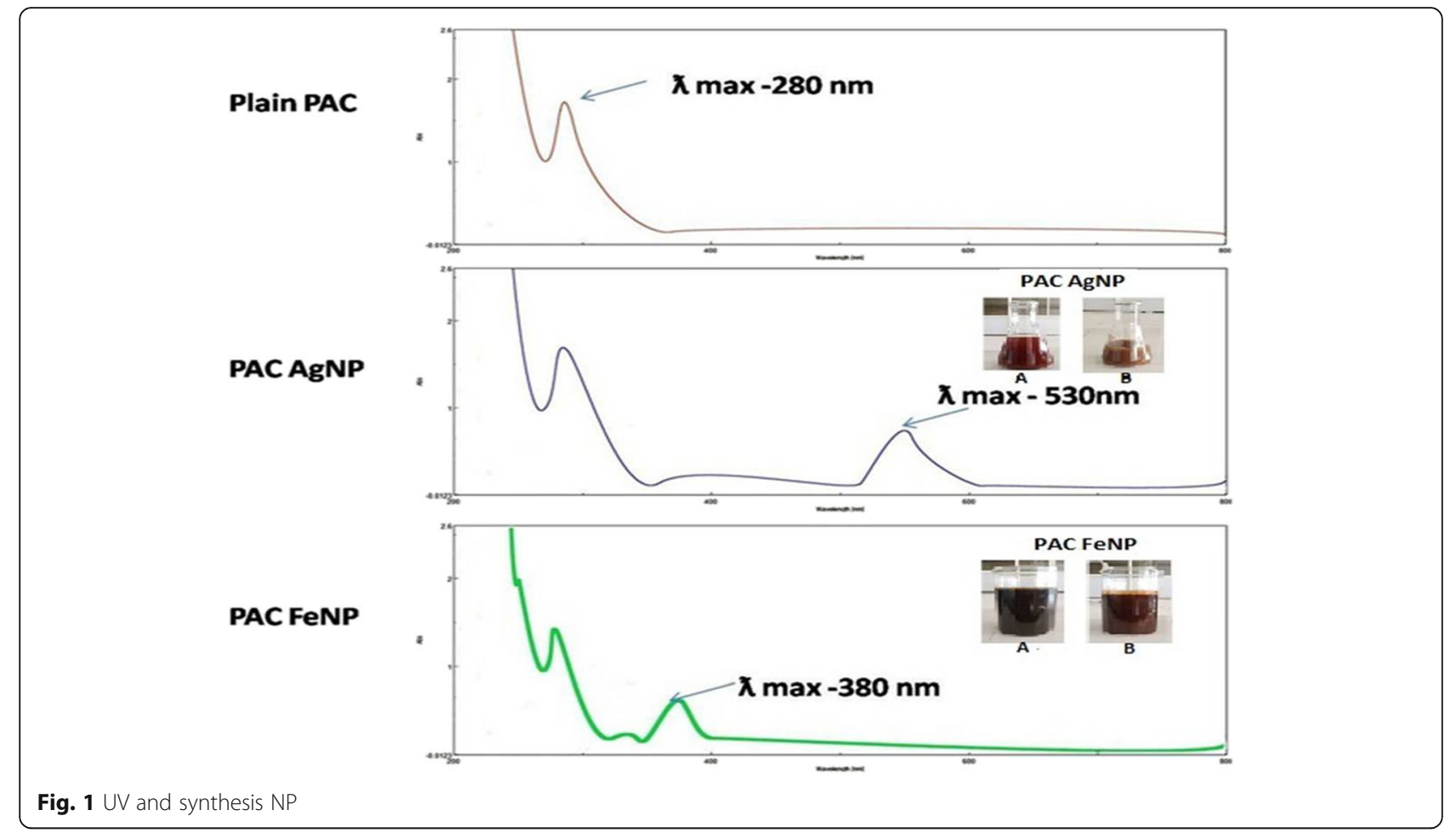

at a voltage of $40 \mathrm{kV}$ and $30 \mathrm{~mA}$ with $\mathrm{Cu} \mathrm{K} \alpha$ radiation in $\theta-2 \theta$ configurations. The crystalline size was determined from the width of the XRD peaks by assuming that they were free from non-uniform strains.

\section{Antimicrobial activity of PAC, PACAgNP, and PACFeNP}

In vitro antimicrobial activity was performed using the agar well diffusion technique [41]. The sterile agar was inoculated with the bacterial culture $(S$. aureus, $P$. aeruginosa, and E. coli) for $48 \mathrm{~h}$ at $37^{\circ} \mathrm{C}$. Antimicrobial activities were tested on nutrient medium against $S$. aureus, $P$. aeruginosa, and $E$. coli, which are representative types of Gram-positive and Gram-negative organisms. Wells were bored by using a sterile borer. Standard solution (ciprofloxacin) and test samples PAC, PACAgNP, and PACFeNP $(5 \mathrm{mg} / \mathrm{mL}$ was prepared by dissolving the test sample in DMSO) were placed into the wells $(80 \mu \mathrm{L})$. Plates were then kept for $2 \mathrm{~h}$ in the refrigerator to enable prediffusion of the extracts into the agar. Finally, the plates were incubated overnight $\left(24 \mathrm{~h}\right.$ at $37{ }^{\circ} \mathrm{C}$.) The antimicrobial activity was determined by measuring the diameter of zone of inhibition $[42,43]$.

\section{In vitro cytotoxicity studies of PAC, PACAgNP, and PACFeNP by using MTT assay}

Human HT29 cell and COLO320DM were obtained from the National Center for Cell Sciences, Pune, MS, India, 411007. The cell cultures were maintained in DMEM supplemented with $10 \%$ fetal bovine serum. The cells were plated at a density of $1 \times 1$ cells per well in a 96-well plate and cultured for $24 \mathrm{~h}$ at $37^{\circ} \mathrm{C}$. The cells were subsequently exposed, the plates were incubated for $24 \mathrm{~h}$, and cell proliferation was measured by adding $10 \mu \mathrm{L}$ of MTT (thiazolyl blue tetrazolium bromide) dye ( $5 \mathrm{mg} / \mathrm{mL}$ in phosphate-buffered saline) per well. The plates were incubated for a further $4 \mathrm{~h}$ at $37^{\circ} \mathrm{C}$ in a humidified chamber containing $5 \% \mathrm{CO}_{2}$. Formazan crystals formed due to reduction of dye by viable cells in each well were dissolved in $200 \mu \mathrm{L}$ DMSO, and absorbance was read at $490 \mathrm{~nm}$.

Finally, the percent cytotoxicity of the compounds was calculated by using the following formula:

$$
\text { Percent Cytotoxicity }=\frac{\text { Reading of control-Reading of treated cells }}{\text { Reading of control }} \times 100
$$

Since the absorbance was directly associated with the number of viable cells, the percent viability was determined from the absorbance.

\section{In vitro cytotoxicity studies of PAC, PACAgNP, and PACFeNP by using SRB assay}

Human HT29 cells and COLO320DM were maintained in DMEM supplemented with $10 \%$ fetal bovine serum. The cells were plated at a density of $1 \times 10^{4}$ cells per well in a 96-well plate and cultured for $24 \mathrm{~h}$ at $37^{\circ} \mathrm{C}$. The cells were subsequently exposed to $100 \mu \mathrm{g} / \mathrm{mL}$ compound. After drug incubation, $50 \mu \mathrm{L}$ TCA $(50 \%)$ was kept for $1 \mathrm{~h}$ at $4{ }^{\circ} \mathrm{C}$. Then, the plate was washed with 
TDW (triple distilled water) and air dried. Thereafter, $100 \mu \mathrm{L}$ SRB dye was added in each well and kept for 30 min at room temperature. Again, the plate was washed three times with $1 \%$ acetic acid and air dried. Finally, $200 \mu \mathrm{L}$ Tris buffer was added, and the absorbance was read at $490 \mathrm{~nm}$.

The percent cytotoxicity of the compounds was calculated by using following formula:

$$
\text { Percent Cytotoxicity }=\frac{\text { Reading of control-Reading of treated cells }}{\text { Reading of control }} \times 100
$$

\section{In vitro cytotoxicity studies of PAC, PACAgNP, and PACFeNP by using Trypan blue assay}

The dye exclusion test is used to find out the number of viable cells present in a cell suspension. It is based on the principle that live cells possess undamaged cell membranes that exclude certain dyes, such as Trypan blue, eosin, or propidium, whereas dead cells do not exclude. In this test, a cell suspension is simply mixed with Trypan blue dye and then visually examined to determine whether cells take up or exclude dye. In the study presented here, a viable cell will have undamaged a clear cytoplasm whereas a non-viable cell will have a blue cytoplasm.

Fifty microliters of cell lines of human HT29 cells and Colo $320 \mathrm{D}$ was taken in micro-centrifuge tube. They were incubated for $3 \mathrm{~min}$ and then added $50 \mu \mathrm{L}$ of all samples of nanoparticles in concentration of $100 \mu \mathrm{g} \mathrm{mL} \mathrm{m}^{-1}$ which were prepared by dissolving in phosphate buffer pH 7.4 and DMSO. They were incubated in $\mathrm{CO}_{2}$ incubator for $3 \mathrm{~min}$, and thereafter, Trypan blue $(0.4 \%) 50 \mu \mathrm{L}$ was added in each tube. They were further incubated for $3 \mathrm{~min}$ in $\mathrm{CO}_{2}$ incubator and analyzed for total viable cells and non-viable cells by using Nubars slide [44].

\section{Antioxidant activity of PAC, PACAgNP, and PACFeNP, by DPPH (2,2-diphenyl-2-picryl hydrazyl hydrate) assay}

The scavenging ability of PAC, PACAgNP, and PACFeNP on the stable free radical was calculated with the method expressed by Mensor et al. [45]. Twenty microliters of PAC, PACAgNP, and PACFeNP solutions was separately added in three labeled test tubes. Subsequently, $0.5 \mathrm{~mL}$ of methanolic solution of DPPH and $0.48 \mathrm{~mL}$ of methanol were added to each test tube, after which all tubes were allowed to react at an ambient temperature for $30 \mathrm{~min}$. The control was prepared as described above, without any extract and nanoparticles. Methanol was used to correct the baseline. After $30 \mathrm{~min}$ of incubation, the discoloration of the purple color was measured under a UV-Visible spectrophotometer. The radical-scavenging activity was determined by the following formula [45]:

$$
\text { Scavenging activity }(\%)=\frac{\mathrm{A}_{\mathrm{abs}}(\text { Control })-\mathrm{A}_{\mathrm{abs}}(\text { Sample })}{\mathrm{A}_{\mathrm{abs}}(\text { Control })} \times 100
$$

where A (control) is the absorbance of control sample PACAgNP and PACFeNP measured at $530 \mathrm{~nm}$ and 275 $\mathrm{nm}$, respectively, and A (control) is the absorbance of PAC measured at $280 \mathrm{~nm}$.

\section{Statistical analysis}

Statistical data of the cytotoxicity were assessed on GraphPad Prism 8 for Windows 64 bit with version 8.0.1 (244). Results were analyzed by one-way ANOVA with Dunnett's post-test analysis of variance. The mean standard error mean (SEM) of all calculated values was shown in each group. A value of $P<0.05,0.01$, or 0.001 was considered statistically significant.

\section{Results}

UV-Vis spectroscopy of PAC, PACAgNP, and PACFeNP

When the aqueous PAC was mixed with aqueous $\mathrm{AgNO}_{3}$ and $\mathrm{FeCl}_{3}$ solution, the color of the solution changed which indicated the formation of silver and iron nanoparticles. This change in color was due to the collective coherent oscillation of conduction electrons at the surface of the nanoparticles that interact with the oscillating electric field of the incident light, a phenomenon called surface plasmon resonance (SPR). This change in color indicated the reduction of $\mathrm{Ag}$ and Fe ions which was traced with UV-Vis spectroscopy. The PAC showed $\max$ at $280 \mathrm{~nm}$, and silver nanoparticle PACAgNP possesses specific wavelength that can absorb at $\max 530 \mathrm{~nm}$, whereas iron nanoparticles PACFeNP exhibit $\max$ at $380 \mathrm{~nm}$ as shown in Fig. 1.

\section{FTIR spectrum of PAC, PACAgNP, and PACFeNP}

In the FTIR of proanthocynidin, fairly sharp peaks at $3223.75,2910.47,1604.74,1515.78,1444.64,1217.89$, and $1018.41 \mathrm{~cm}^{-1}$ were observed, which indicate the presence of the functional group present in the compound. However, the aromatic at 1604.74 (C-C-valence) $\mathrm{cm}^{-1}$, the $\mathrm{OH}$ phenolic at $3223.75(\mathrm{O}-\mathrm{H}$-valence) and 2910.47 (C-H-valence, arene), alkane $\left(\mathrm{OCH}_{3}\right)$, the methoxylic at $1217.89 \mathrm{~cm}^{-1}$, and $\mathrm{C}-\mathrm{O}$ stretching at 1044.64 appeared in the IR spectrum of complex as shown in Fig. 2a.

\section{PACAgNP}

These characteristic vibrations after reduction of $\mathrm{Ag}+$ ions were shifted to new peaks at 3222.80, 2888.50, $1600.76,1507.93,1425.35,1188.54$, and $1025.79 \mathrm{~cm}^{-1}$, which indicated the presence of the functional group present in the compound. However, the aromatic at 1600.76 (C-C-valence) $\mathrm{cm}^{-1}$, the $\mathrm{OH}$ phenolic at 3222.80 (O-H-valence) and 2888.50 (C-H-valence, 


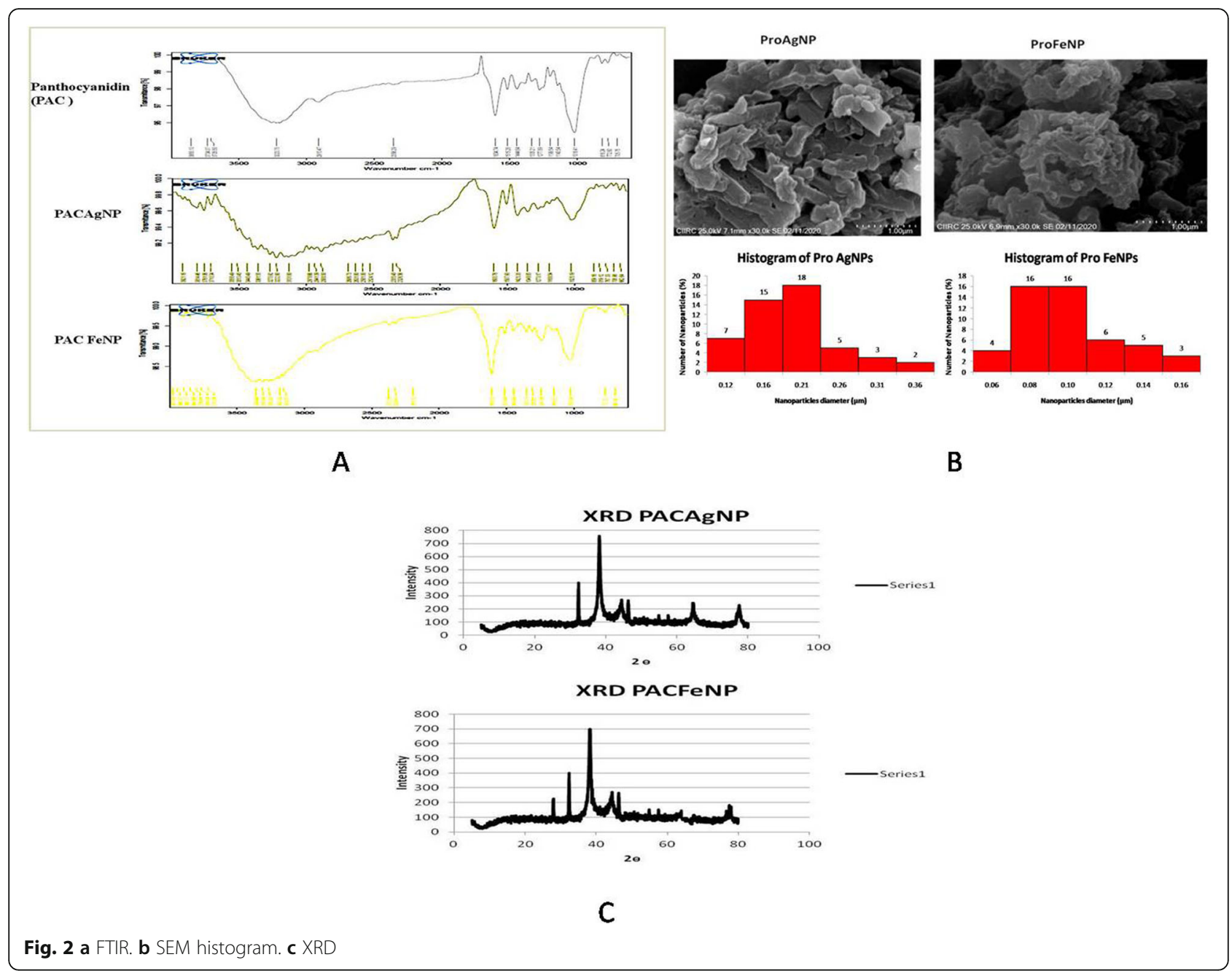

arene), alkane $\left(\mathrm{OCH}_{3}\right)$, the methoxylic at $1188.54 \mathrm{~cm}^{-1}$, and $\mathrm{C}-\mathrm{O}$ stretching at 1025.79 appeared in the IR spectrum of complex as shown in Fig. 2a.

In addition, bio-reduction showed that the 3222.80, 2888.50 , and $1025.79 \mathrm{~cm}^{-1}$ bands were suppressed in the AgNP. Proanthocynidin and NPs showed similar absorption bands, indicating that NPs might be stabilized by proanthocynidin. On the basis of the orange, yellow, and brownish green color of the biomass and the groups suggested by FTIR analysis, it was hypothesized that proanthocynidin may be involved in silver nanoparticle synthesis.

\section{PACFeNP}

These characteristic vibrations after reduction of Fe3+ ions were shifted to new peaks at 3310.40, 2900.05, $1610.53,1513.64,1448.60,1149.07$, and $1025.38 \mathrm{~cm}^{-1}$, which indicated the presence of the functional group present in the compound. However, the aromatic at 1610.53 (C-C-valence) $\mathrm{cm}^{-1}$, the $\mathrm{OH}$ phenolic at 3310.40 (O-H-valence) and 2900.05 (C-H-valence, arene), alkane $\left(\mathrm{OCH}_{3}\right)$, the methoxylic at $1149.07 \mathrm{~cm}^{-1}$, and $\mathrm{C}-\mathrm{O}$ stretching at 1025.38 appear in the IR spectrum of complex as shown in Fig. 2a. In addition, bio-reduction showed that the 3310.40, 2900.05, and $1149.07 \mathrm{~cm}^{-1}$ bands were suppressed in the FeNP. Proanthocynidin and NPs showed similar absorption bands, indicating that NPs might be stabilized by proanthocynidin. On the basis of the orange, yellow, and blackish color of the biomass and the groups suggested by FTIR analysis, it was hypothesized that proanthocynidin may be involved in iron nanoparticle synthesis.

\section{SEM and histogram analysis of PACAgNP and PACFeNP}

A scanning electron microscope was used to analyze the structure of PACAgNP and PACFeNP nanoparticles that are developed and represented in Fig. 2b. The nanoparticles formed were aggregated having a size range of 100 to $120 \mathrm{~nm}$. This aggregation of the nanoparticles can be minimized or prohibited by increasing the concentration of the proanthocynidin extract. Histograms of both the nanoparticles have been represented in Fig. 2b exhibiting 
average particle size PACFeNP $0.09083+0.02627 \mu \mathrm{m}$ and PACAgNP $0.17746+0.05784 \mu \mathrm{m}$.

\section{$X R D$ spectrum of PACAgNP and PACFeNP}

The XRD pattern of the synthesized silver and iron nanoparticles formed using proanthocynidin is shown in Fig. 2c. The diffraction peak at $2 \theta=38^{\circ}$ and subsequent higher order reflections can be indexed to the Ag and other facets of silver nanoparticles by comparing JCPDS file no: 89-3722; in case of PACFeNP, the peak shown at $2 \theta=33^{\circ}$ corresponds to the iron compared with standard XRD for iron (JCPDS data: pdf no 39:1346).

The XRD spectrum also revealed a weak peak around $2 \theta=30^{\circ}$, which can be attributed to the phytochemical components. It, thus, confirmed that the nanoparticles formed on the membrane consisted of crystalline. XRD indicated possible multicomponent product formation at higher energy.

\section{Antibacterial activity of PAC, PACAgNP, and PACFeNP}

The zones of inhibition revealed that there is very little antimicrobial potential of PAC, PACAgNP, and PACFeNP against Pseudomonas aeruginosa, Staphylococcus aureus, and $E$ coli. The results are highlighted in Table 1, and the zone of inhibition is depicted in Fig. 3.

\section{Results of cytotoxicity of PAC, PACAgNP, and PACFeNP}

The results of cytotoxicity assay by MTT and SRB assay have been presented in Table 2 with respect to two different colon cancer cell lines namely COLO320DM and HT29. A variation in the results of different assay was observed; however, the silver nanoparticles exhibited better activity than pure PAC in both the methods. The results of MTT assay against HT29 demonstrated that PACAgNP showed maximum $63.34 \pm 1.64 \%$ inhibition represented in Fig. 4x (A). In case of COLO320DM, silver nanoparticles exhibited $64.27 \pm 1.63 \%$ inhibition as represented in Fig. 4x (B), whereas the SRB assay of PAC, PACAgNP, and PACFeNP against HT29 revealed $69.21 \pm 1.86 \%$ inhibition by PACAgNP as shown in Fig. $4 \mathrm{x}(\mathrm{C})$. In case of COLO320DM SRB assay, a maximum of $71.6 \pm 1.97 \%$ inhibition was exhibited by silver nanoparticles as depicted in Fig. 4x (D).
The results of Trypan blue assay revealed that silver nanopaticles PACAgNP showed $85.63 \pm 0.27 \%$ nonviability of COLO320DM cell line when observed on a Motic microscope, whereas iron nanoparticles PACFeNP exhibited $94.57 \pm 0.36 \%$ inhibition of HT29 cell lines as represented in Table 3.

\section{Results of DPPH (2,2-diphenyl-2-picryl hydrazyl hydrate) assay of PAC, PACAuNP, and PACFeNP}

The DPPH activity results demonstrated effective free radical percent scavenging potential of PAC, PACAuNP, and PACFeNP as depicted in Fig. 4y. As compared to ascorbic acid (standard), the concentration response curves of DPPH radical-scavenging activity of PAC, PACAuNP, and PACFeNP are shown in Table 4. It was observed that PACAgNPs were more effective than PAC extract and PACFeNPs. At a concentration of $50 \mu \mathrm{g}$ $\mathrm{mL}^{-1}$, the scavenging activity of PACAgNPs was observed to be $20.83 \pm 0.33 \%$, while at similar concentration, for the PACFeNPs it was reported to be $18.06 \pm$ $0.60 \%$. The outcome of antioxidants on DPPH is thought to be due to their hydrogen donating ability.

\section{Discussion}

Engineered nanomaterials showed imperative benefits due to their unique nanostructure, along with their significant properties for the designed applications [46]. Metallic NPs have been synthesized using several different methods such as chemical reduction, electrochemical, microbiological reduction, ultrasonication method, and microwave radiation [47]. The present research work is focused on green synthesis of silver and iron nanoparticles of isolated proanthocynidin from grape seed extract. It is an eco-friendly, economical, easy, and rapid method of development of metal nanoparticles with minimum usage of hazardous chemicals. The developed silver and iron nanoparticles were characterized by UV spectroscopy which showed the change in absorbance after development of nanoparticles. FTIR spectrum provides the information about the chemical change of the functional groups involved in bio-reduction [48, 49]. The FTIR spectra of developed nanoparticles confirmed the formation of silver and iron nanoparticles as characteristic vibrations after reduction of $\mathrm{Ag}+$ ions were

Table 1 Results of antibacterial activity of PAC, PACAgNP, and PACFeNP against selected microbial strains

\begin{tabular}{lllll}
\hline Sr. & Sample name & \multicolumn{2}{l}{ Zone of inhibition diameter $(\mathrm{mm})$ against the selected microorganisms } \\
\cline { 3 - 5 } & & Pseudomonas aeruginosa & Staphylococcus aureus & E. coli \\
\hline 1 & PAC pure & $6.00 \pm 0.10$ & 0.0 & 0.00 \\
2 & PACAgNP & $7.0 \pm 0.11$ & $12.00 \pm 0.16$ & $6.00 \pm 0.13$ \\
3 & PACFeNP & $6.0 \pm 0.14$ & $6.0 \pm 0.12$ & 0.00 \\
4 & Ciprofloxacin std. & $35 \pm 0.11$ & $38 \pm 0.13$ & $40 \pm 0.12$ \\
\hline
\end{tabular}

Values are expressed in triplicate mean SD 


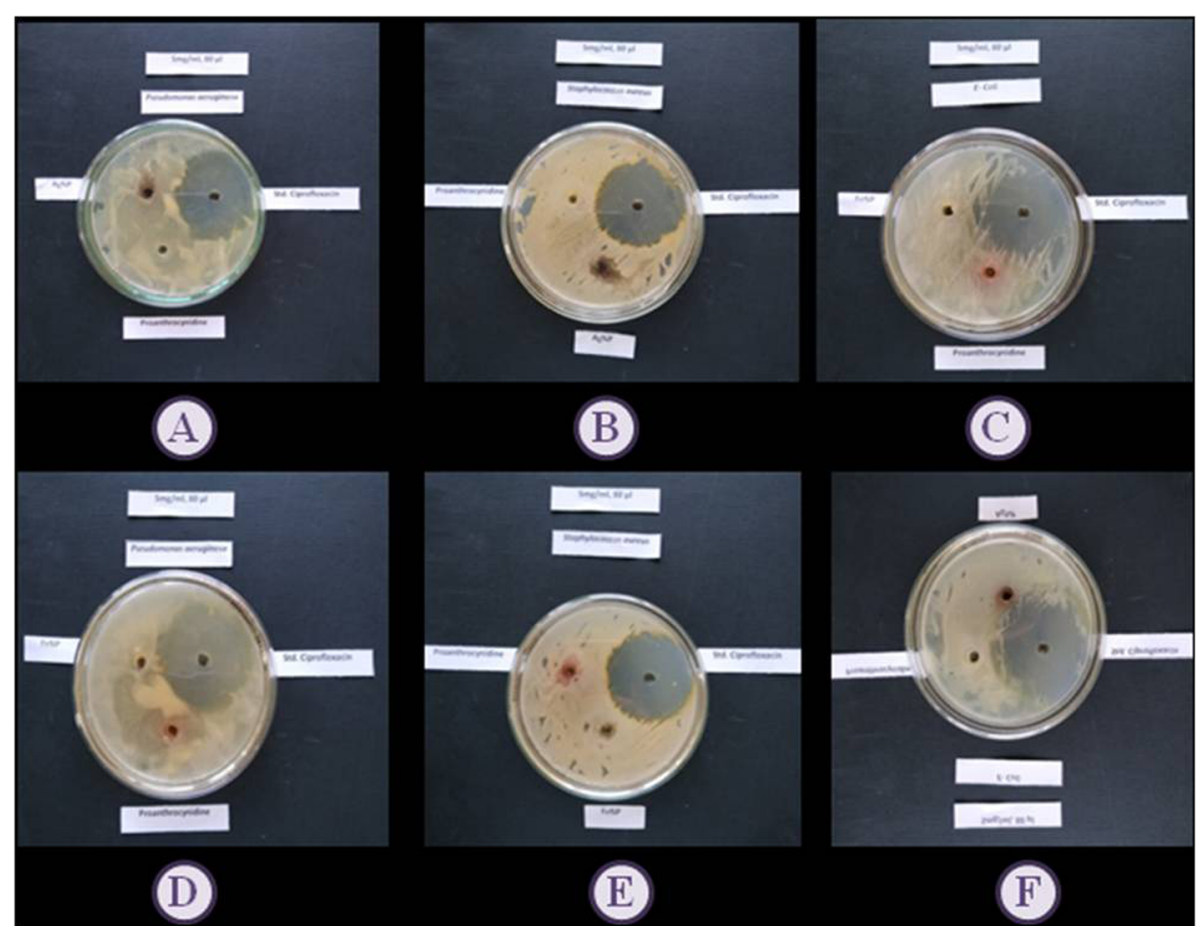

Fig. 3 Antimicrobial activity

shifted to new peaks at 3222.80, 2888.50, 1600.76, $1507.93,1425.35,1188.54$, and $1025.79 \mathrm{~cm}^{-1}$. And characteristic vibrations after reduction of $\mathrm{Fe} 3+$ ions were shifted to new peaks at 3310.40, 2900.05, 1610.53, 1513.64, 1448.60, 1149.07, and $1025.38 \mathrm{~cm}^{-1}$. Also, characteristic color change can be attributed to the surface plasmon resonance of deposited AgNPs. And it clearly indicated the development of nanoparticles [50].

The size of nanoparticles and its morphology were clearly observed in the SEM images. The average size for

Table 2 Results of cytotoxicity of PAC, PACAgNPs, and PACFeNP by MTT and SRB assay using COLO320DM and HT29 cell lines

\begin{tabular}{|c|c|c|c|}
\hline Compound & Mean OD & Percent inhibition & Percent viability \\
\hline \multicolumn{4}{|c|}{ MTT assay against HT29 (control—0.321) } \\
\hline Proanthocynidin plain & 0.161 & $49.53 \pm 1.54$ & $47.13 \pm 3.32$ \\
\hline Proanthocynidin AgNP & 0.117 & $63.34 \pm 1.64$ & $36.65 \pm 1.64$ \\
\hline Proanthocynidin FeNP & 0.129 & $59.39 \pm 1.84$ & $40.60 \pm 1.84$ \\
\hline \multicolumn{4}{|c|}{ MTT assay against COLO320DM (control—0.384) } \\
\hline Proanthocynidin plain & 0.146 & $61.49 \pm 1.66$ & $35.51 \pm 1.66$ \\
\hline Proanthocynidin AgNP & 0.137 & $64.27 \pm 1.63$ & $35.72 \pm 1.63$ \\
\hline Proanthocynidin FeNP & 0.142 & $63.17 \pm 1.63$ & $36.49 \pm 2.07$ \\
\hline \multicolumn{4}{|c|}{ SRB assay against HT29 (control—0.292) } \\
\hline Proanthocynidin plain & 0.204 & $30.71 \pm 1.88$ & $69.29 \pm 1.88$ \\
\hline Proanthocynidin AgNP & 0.090 & $69.21 \pm 1.86$ & $30.78 \pm 1.86$ \\
\hline Proanthocynidin FeNP & 0.115 & $60.57 \pm 2.20$ & $39.43 \pm 2.20$ \\
\hline Proanthocynidin plain & 0.204 & $30.71 \pm 1.88$ & $69.29 \pm 1.88$ \\
\hline \multicolumn{4}{|c|}{ SRB assay against COLO320DM (control—0.252) } \\
\hline Proanthocynidin plain & 0.209 & $17.11 \pm 1.72$ & $82.89 \pm 1.72$ \\
\hline Proanthocynidin AgNP & 0.073 & $71.6 \pm 1.97$ & $28.4 \pm 1.97$ \\
\hline Proanthocynidin FeNP & 0.141 & $44.60 \pm 2.18$ & $55.39 \pm 2.18$ \\
\hline
\end{tabular}

Values are expressed in triplicate mean SD 


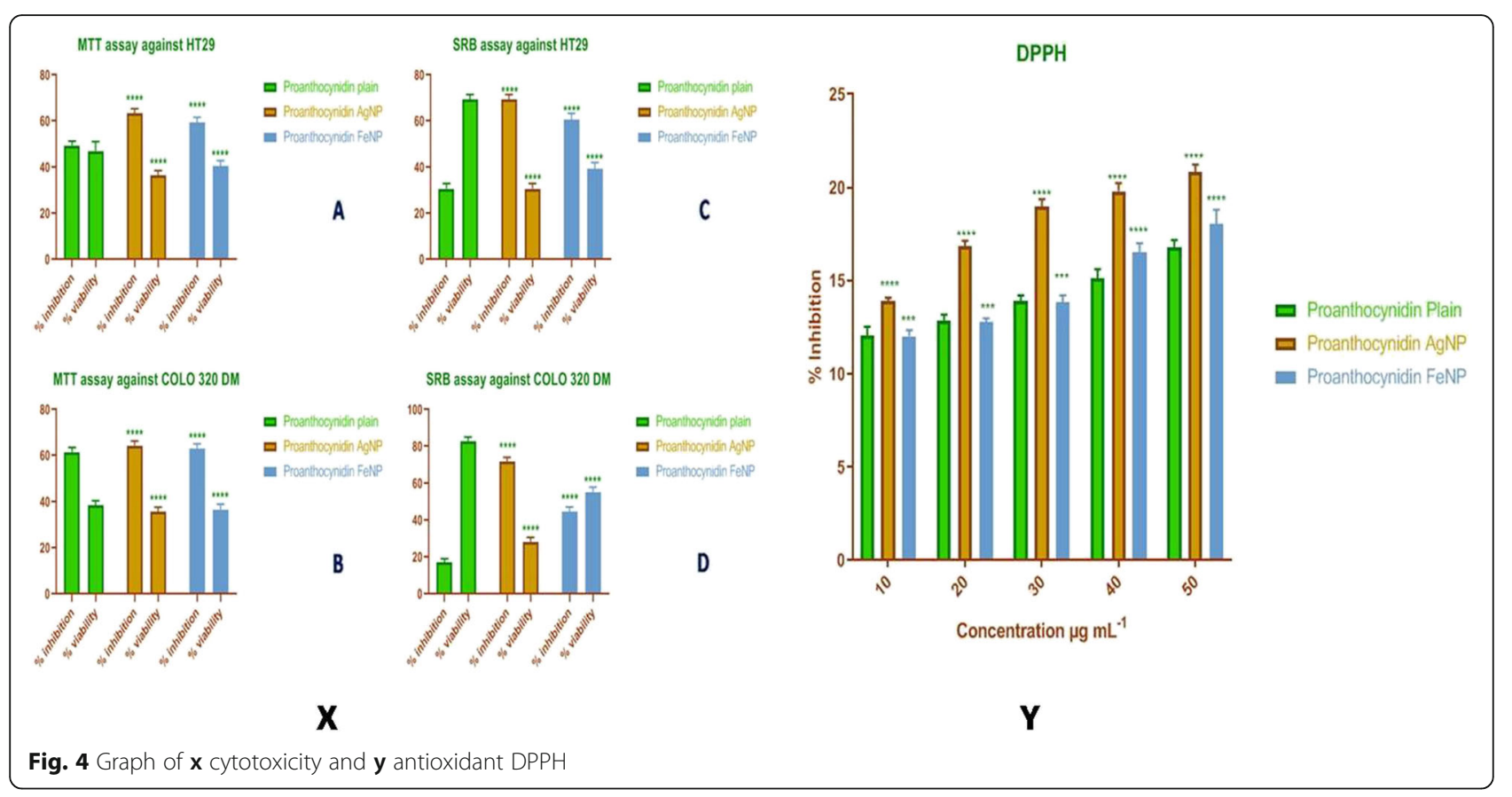

PACFeNP was observed to be $0.09083+0.02627 \mu \mathrm{m}$ and $0.17746+0.05784 \mu \mathrm{m}$ for PACAgNP. The XRD results revealed weak peak at $2 \theta=30^{\circ}$ for phytoconstituent, whereas diffraction peak at $2 \theta=38^{\circ}$ was observed for silver nanoparticles and iron nanoparticles showed the peak at $2 \theta=33^{\circ}$.

In case of antimicrobial activity, the developed silver and iron nanoparticles exhibited little antimicrobial potential as compared to pure proanthocynidin. Metal NPs increase the antibacterial potential due to the formation of reactive oxygen species (ROS), developed from different types of iron oxide nanoparticles like $\mathrm{FeO}, \mathrm{Fe} 2 \mathrm{O} 3$, and $\mathrm{Fe} 3 \mathrm{O} 4$. The free radical produced in the reaction causes intracellular stresses that can damage the DNA of the cell [51].

The in vitro cytotoxicity results against HT29 and COLO320DM showed that PACAgNP exhibited 63.34 \pm $1.64 \%$ inhibition (MTT assay) and $69.21 \pm 1.86 \%$ inhibition (SRB assay) against HT29. In case of COLO320DM, PACAgNP demonstrated $64.27 \pm 1.63 \%$ inhibition (MTT assay) and $71.6 \pm 1.97 \%$ inhibition (SRB assay).

In DPPH assay, PACFeNP and PACAgNP exhibited $18.06 \pm 0.60 \%$ and $20.83 \pm 0.33 \%$ inhibition, respectively.
The obtained parameters of the characterization and evaluation of the nanoparticles clearly revealed that as compared to proanthocynidin, the silver and iron nanoparticles possess better antioxidant and anticancer potential against colorectal cancer. Thus, the use of isolated phytoconstituent(s) which are devoid of side effects and promoting better absorption and cellular uptake owing to their nanosize will certainly achieve effective targeting and has to be provided greater attention as a newer research area. Also, several review papers have been published about the synthesis of silver nanoparticles using natural polymers like k-Carrageenan and synthetic polymers like poly vinyl pyrrolidone and polyethylene glycol to improve the strength and stability of nanoparticles. As per the study of Moustafa, the use of natural and synthetic polymer for the development of silver nanoparticles opened up new research area in medicinal and biological field along with food industry [52].

\section{Conclusion}

We have successfully synthesized PACAgNPs and PACFeNPs using proanthocynidin isolated from grape seed extract by employing a green synthesis method which is

Table 3 Results of cytotoxicity of PAC, PACAgNPs, and PACFeNP by using Trypan blue assay

\begin{tabular}{lllllll}
\hline Sr. & Drug & COLO320DM & & & HT29 & \\
\cline { 3 - 4 } & & Percent viability & Percent non-viable & & Percent viability & Percent non-viable \\
\hline 1 & Proanthocynidin plain & $31.45 \pm 0.49$ & $68.88 \pm 0.36$ & & $25.48 \pm 0.31$ & $74.70 \pm 0.58$ \\
2 & Proanthocynidin AgNP & $14.89 \pm 0.30$ & $85.63 \pm 0.27$ & & $9.56 \pm 0.26$ & $90.23 \pm 0.43$ \\
3 & Proanthocynidin FeNP & $25.7 \pm 0.42$ & $74.5 \pm 0.28$ & $5.34 \pm 0.18$ & $94.57 \pm 0.36$ \\
\hline
\end{tabular}

Values are expressed in triplicate mean SD 
Table 4 Antioxidant activity of DPPH radical-scavenging activity

\begin{tabular}{|c|c|c|c|c|}
\hline Concentrations, $\mu \mathrm{g} \mathrm{mL}^{-1}$ & Standard, percent inhibition & PAC, percent inhibition & PACAgNPs, percent inhibition & PACFeNPs, percent inhibition \\
\hline 10 & $93.29 \pm 0.60$ & $12.07 \pm 0.37$ & $13.92 \pm 0.13$ & $12.01 \pm 0.27$ \\
\hline 20 & $95.13 \pm 0.54$ & $12.86 \pm 0.25$ & $16.83 \pm 0.24$ & $12.78 \pm 0.16$ \\
\hline 30 & $96.16 \pm 0.17$ & $13.89 \pm 0.24$ & $18.95 \pm 0.33$ & $13.83 \pm 0.30$ \\
\hline 40 & $97.76 \pm 0.29$ & $15.11 \pm 0.41$ & $19.80 \pm 0.35$ & $16.52 \pm 0.40$ \\
\hline 50 & $98.73 \pm 0.18$ & $16.79 \pm 0.32$ & $20.83 \pm 0.33$ & $18.06 \pm 0.60$ \\
\hline IC50 & - & $12.50 \pm 0.30$ & $7.37 \pm 0.27$ & $9.31 \pm 0.22$ \\
\hline
\end{tabular}

Values are expressed in triplicate mean SD

relatively simple and environmentally benign. PACAgNPs and PACFeNPs were obtained, with particles between 50 and $100 \mathrm{~nm}$ in size. It is easy and costeffective and does not involve any harmful and poisonous chemicals. All the other characterization like UV, FTIR, XRD, and SEM confirmed the development of nanoparticles. We have observed significant antioxidant activity and free radical-scavenging capacities. PACAgNPs and PACFeNPs exhibited a little antibacterial activity against the selected strains of microbes. In a nutshell, the study showed that the developed NPs from the isolated PAC exhibit beneficial antioxidant and anticancer potential when assessed by three different in vitro assay methods with specifically colon cancer cell lines. Thus, it may open up a new opportunity for anticancer therapies that need further research.

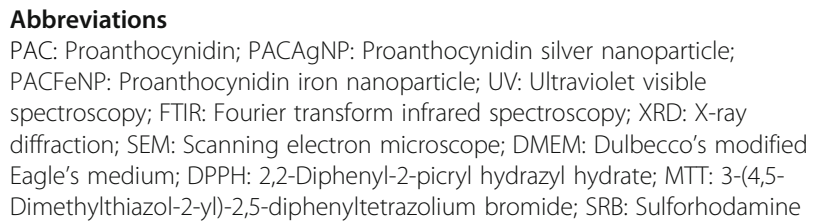

Abbreviations

PAC: Proanthocynidin; PACAgNP: Proanthocynidin silver nanoparticle; PACFeNP: Proanthocynidin iron nanoparticle; UV: Ultraviolet visible spectroscopy; FTIR: Fourier transform infrared spectroscopy; XRD: X-ray diffraction; SEM: Scanning electron microscope; DMEM: Dulbecco's modified Eagle's medium; DPPH: 2,2-Diphenyl-2-picryl hydrazyl hydrate; MTT: 3-(4,5Dimethylthiazol-2-yl)-2,5-diphenyltetrazolium bromide; SRB: Sulforhodamine

\section{Acknowledgements}

The authors are thankful to the Secretary of KES Society Kasegaon, and Principal of Rajarambapu College of Pharmacy, Kasegaon, Sangli, Maharashtra, for providing facilities. We are also thankful to the managing director Influx Healthcare, Mumbai, for providing pure phytoconstituent markers. Dr. Sandip Patil MD Biocyte Institute of Research and Development (BiRD) Sangli $\mathrm{MH}$

\section{Authors' contributions}

The work was carried out by DSR during the period of study for the degree of doctor of philosophy under the supervision of SDB. All the laboratory work including preparation and results has been carried out by KPS and DSR. The analysis and interpretation of the results were carried out by MAB, GHW, and NRJ. The manuscript was written by KPS and revised by DSR and SDB. All the authors have read and approved the manuscript.

\section{Funding}

No any funding received for this work.

\section{Availability of data and materials}

All the data required for the processing of the conclusions are presented in the "Results" section. Supporting data was included separately.

Ethics approval and consent to participate

Not applicable
Consent for publication

Not applicable

\section{Competing interests}

The authors declare that they have no competing interests.

\section{Author details}

${ }^{1}$ Department of Pharmaceutics, Rajarambapu College of Pharmacy, Kasegaon, Walwa, Sangli, Maharashtra 415404, India. ${ }^{2}$ Department of Pharmaceutical Chemistry, Rajarambapu College of Pharmacy, Kasegaon, Walwa, Sangli, Maharashtra 415404, India. ${ }^{3}$ Department of Pharmaceutics, Bharati Vidyapeeth College of Pharmacy, Kolhapur, Maharashtra 416013, India.

Received: 27 May 2020 Accepted: 4 August 2020

Published online: 20 August 2020

\section{References}

1. Jemal A, Murray T, Ward E (2005) Cancer statistics. CA Cancer J Clin 55:1030

2. Huang S, Yang N, Liu Y, Gao J, Huang T, Hu L, Zhao J, Li Y, Li C, Zhang X (2012) Grape seed proanthocyanidins inhibit colon cancer-induced angiogenesis through suppressing the expression of VEGF and Ang1. Int J Mol Med 30:1410-1416

3. Todkar SS, Bhutkar MA, Randive DS, Wadkar GH, Bhinge SD (2017) Risk and management of nanoparticles - an overview. Int J Phar Res Life Sci 1:1-13

4. Environmental Protection Agency, (2007). "Nanotechnology white paper," USEPA 100/B-07/001.

5. Chavan RR, Bhinge SD, Bhutkar MA, Randive DS, Wadkar GH, Todkar SS, Urade MN (2020) Characterization, antioxidant, antimicrobial and cytotoxic activities of green synthesized silver and iron nanoparticles using alcoholic Blumea eriantha DC plant extract. Mater Today Commun 24:101320. https:// doi.org/10.1016/j.mtcomm.2020.101320

6. Sulaiman GM, Hussien HT, Saleem MMNM (2015) Biosynthesis of silver nanoparticles synthesized by Aspergillus flavus and their antioxidant, antimicrobial and cytotoxicity properties. Bull Mater Sci 38(3):639-644

7. Al-Shmgani HSA, Mohammed WH, Sulaiman GM, Saadoon AH (2017) Biosynthesis of silver nanoparticles from Catharanthus roseus leaf extract and assessing their antioxidant, antimicrobial, and wound-healing activities. Artif Cell Nanomed B 45(6):1234-1240. https://doi.org/10.1080/21691401. 2016.1220950

8. Thakkar KN, Mhatre SS, Parikh RY (2010) Biological synthesis of metallic nanoparticles. Nanomedicine 6:257-262

9. Panigrahi S, Kundu S, Ghosh SK, Nath S, Pal T (2004) General method of synthesis for metal nanoparticles. J Nanopart Res 6:411-414

10. The Energy and Resources Institute (2010) Nanotechnology development in India: building capability and governing the technology. Briefing Paper, TERI

11. Herlekar M, Barve S, Kumar R (2014) Plant-mediated green synthesis of iron nanoparticles. J Nanomater:1-9

12. Biao L, Tan S, Zhang X, Gao J, Liu Z, Fu Y (2018) Synthesis and characterization of proanthocyanidins-functionalized Ag nanoparticles. Colloids Surf B: Biointerfaces 169:438-443

13. Gurushankar K, Gohulkumar M, Prasad NR, Rishnakumar N (2014) Synthesis, characterization and in vitro anti-cancer evaluation of hesperetin-loaded nanoparticles in human oral carcinoma (KB) cells. Adv Nat Sci Nanosci Nanotechnol 5:1-10 
14. Randive DS, Sayyad SF, Bhinge SD, Bhutkar MA (2016) Preparation of Arjunārișța using microbes isolated from woodfordia fruticosa flowers (dhayati). Anc Sci Life 36:42-47

15. Randive DS, Bhinge SD, Bhutkar MA, Joshi SR, Patil PD, Shejawal KP, Thorat MS, Mulla AS (2020) Formulation and evaluation of Herbal cough remedy from extract of Calendula officinalis L. Indian Drugs 57(04):52-58

16. Randive DS, Bhutkar MA, Bhinge SD (2020) Formulation and evaluation of Lipstick, Rouge and Eye shadow using colored pigment from the extract of Piper betel and Acacia catechu. Indian Drugs 57(02):59-66

17. Randive DS, Bhinge SD, Wadkar GH, Sayyad SF, Bhutkar MA (2016) Comparative standardization of marketed formulations of fermented biomedicine - arjunaristha Indonesian. J Pharmacoepidemiol 27:220-225

18. Randive DS, Bhutkar MA, Bhinge SD, Shejwal KP, Patil PD, Mane SA (2019) Hypoglycemic effects of Lagenaria siceraria, Cynodon dactylon and Stevia rebaudiana extracts. J Herb Pharmacother 8:51-55

19. Gabetta B, Fuzzati N, Griffini A, Lolla E, Pace R, Ruffilli T, Peterlongo F (2000) Characterization of proanthocyanidins from grape seeds. Fitoterapia 71:162-175

20. Kijima I, Phung S, Hur G, Kwok SL, Chen S (2006) Grape seed extract is an aromatase inhibitor and a supressor of aromatase expression. Cancer Res 66: 5960-5967

21. Skerget M, Kotnik P, Hadolin M, Hras AR, Simonic M, Knez Z (2005) Phenols, proanthocyanidins, flavones and flavonols in some plant materials and their antioxidant activities. Food Chem 89:191-198

22. Quideau S, Deffieux D, Douat-Casassus C, Pouysegu L (2011) Plant polyphenols: chemical properties, biological activities, and synthesis. Angew Chem Int Ed 50:586-621

23. Bagchi D, Bagchi M, Stohs SJ, Das DK, Ray SD, Kuszynski CA, Joshi SS, Pruess HG (2000) Free radicals and grape seed proanthocyanidin extract: importance in human health and disease prevention. Toxicology 148:187-197

24. Kim H, Hall P, Smith M, Kirk M, Prasain JK, Barnes S, Grubbs C (2004) Chemoprevention by grape seed extract and genistein in carcinogeninduced mammary cancer in rats is diet dependent. J Nutr 134: 3445S-3452S

25. Seeram NP, Adams LS, Hardy ML, Heber D (2004) Total cranberry extract versus its phytochemical constituents: antiproliferative and synergistic effects against human tumor cell lines. J Agric Food Chem 52:2512-2517

26. Vayalil PK, Mittal A, Kativar SK (2004) Proanthocyanidins from grape seeds inhibit expression of matrix metalloproteinases in human prostate carcinoma cells, which is associated with the inhibition of MAPK and NF kappa B. Carcinogenesis. 25:987-995

27. Hong H, Yi-Min Q (2006) Grape seed proanthocyanidin extract induced mitochondria-associated apoptosis in human acute myeloid leukaemia 14. 3D10 cells. Chin Med J 119:417-421

28. King M, Chatelain K, Farris D, Jensen D, Pickup J, Swapp A, O'Malley S, Kingsley K (2007) Oral squamous cell carcinoma proliferative phenotype is modulated by proanthocyanidins: a potential prevention and treatment alternative for oral cancer. BMC Complement Altern Med 7:1-12

29. ERasmussen S, Frederiksen H, Struntze Krogholm K, Oulsen L (2005) Dietary proanthocyanidins: occurrence, dietary intake, bioavailability, and protection against cardiovascular disease. Mol Nutr Food Res 49:159-174

30. Kaur M, Singh RP, Gu M, Agarwal R, Agarwal C (2006) Grape seed extract inhibits in vitro and in vivo growth of human colorectal carcinoma cells. Clin Cancer Res 12:6194-6202

31. Ying YC, Grayson KJ, Patricia IO, Andrew L (2013) Waterhouse, Bioavailability of intact proanthocyanidins in the rat colon after ingestion of grape seed extract. Agric Food Chem 61:121-127

32. Engelbrecht AM, Mattheyse M, Ellis B, Loos B, Thomas M, Smith R, Peters S, Smith C, Myburgh K (2007) Proanthocyanidin from grape seeds inactivates the PI3-kinase/PKB pathway and induces apoptosis in a colon cancer cell line. Cancer Lett 258:144-153

33. Keen CL, Holt RR, IOteiza P, Fraga CG, Schmitz HH (2005) Cocoa antioxidants and cardiovascular health. Am J Clin Nutr 81:298S-303S

34. Prior RL, Gu L (2005) Occurrence and biological significance of proanthocyanidins in the American diet. Phytochemistry 66:2264-2280

35. Katiyar SK (2007) UV-induced immune suppression and photocarcinogenesis: Chemoprevention by dietary botanical agents. Cancer Lett 255(1):1-11

36. Seiler N, Chaabi M, Roussi S, Gosse F, Lobstein A, Raul F (2006) Synergism between apple procyanidins and lysosomotropic drugs: potential in chemoprevention. Anticancer Res 26:3381-3385
37. Caili FU, Loo AEK, Chia FPP, Huang D (2007) Oligomeric proanthocyanidins from mangosteen pericarps. J Agric Food Chem 55:7689-7694

38. Abdel-Mohsen AM, Abdel-Rahman RM, Fouda MMG, Vojtova L, Uhrova L, Hassan AF, Al-Deyab SS, El-Shamy IE, Jancar J (2014) Preparation, characterization and cytotoxicity of schizophyllan/silver nanoparticle composite. Carbohydr Polym 102:238-245

39. Phull AR, Abbas Q, Ali A, Raza H, Jakim S (2016) Antioxidant, cytotoxic and antimicrobial activities of green synthesized silver nanaoparticlesfromcrude extract of Bergenia ciliata. Future J Pharm Sci 2:31-36

40. Raju C, Bharadwaj MS, Prem K, Satyanandam K (2016) Green synthesis of iron nanoparticles using Albizia lebbeck leaves for synthetic dyes decolorization. Int J Sci Eng Tech Res 5:3429-3434

41. Bhinge SD, Hogade MG, Savali AS, Hariprassana RC, Magdum CS (2013) Antibacterial activity of bark extract of ficus glomerataroxb against some gram positive and gram negative bacteria. Indian Drugs 50:44-47

42. Bhinge SD, Bhutkar MA, Randive DS, Wadkar GH, Todkar SS, Kakade PM, Kadam PM (2017) Formulation development and evaluation of antimicrobial polyherbal gel. Ann Pharm Fr 75:349-358

43. Bhinge SD, Bhutkar MA, Randive DS, Wadkar GH, Kamble SY, Kalel PD, Kadam SS (2019) Formulation and evaluation of polyherbal gel containing extracts of Azadirachta indica, Adhatoda vasica, Piper betle, Ocimum tenuiflorum and Pongamia pinnata. J Res Phar 23(1):44-54

44. Mosmann T (1983) Rapid colorimetric assay for cellular growth and survival: application to proliferation and cytotoxicity assays. J Immunol Methods 65: $55-63$

45. Mensor LL, Menezes FS, Leitao GG, Reis AS, Dos Santos TC, Coube CS (2001) Screening of Brazilian plant extracts for antioxidant activity by the use of DPPH free radical method. Phytother Res 15:127-130

46. Dahlous KA, Abd-Elkader OH, Fouda MMG, AL Othmana ZA, El-Fahama A, (2019) Eco-friendly method for silver nanoparticles immobilized decorated silica: synthesis \& characterization and preliminary antibacterial activity, J Taiwan Inst Chem E 95: 324-331.

47. Hussein J, El-Naggar ME, Fouda MMG, Morsy OM, Ajarem JS, Almalki AM, Allam AA, Mekawi EM (2020) The efficiency of blackberry loaded AgNPs, AuNPs and Ag@AuNPs mediated pectin in the treatment of cisplatin-induced cardiotoxicity in experimental rats. Int J Biol Macromol 159:1084-1093. https://doi.org/10.1016/j.ijbiomac.2020.05.115

48. Sulaiman GM, Ali EH, Jabbar II, Saleem AH Synthesis, characterization, antibacterial and cytotoxic effects of silver nanoparticles. Dig J Nanomater Bios 9(2):787-796

49. Sulaiman GM, Tawfeeq AT, Naji AS (2018) Biosynthesis, characterization of magnetic iron oxide nanoparticles and evaluations of the cytotoxicity and dna damage of human breast carcinoma cell lines. Artif Cells Nanomed Biotechnol 46(6):1215-1229. https://doi.org/10.1080/21691401.2017.1366335

50. Taha ZK, Hawar SN, Sulaiman GM (2019) Extracellular biosynthesis of silver nanoparticles from Penicillium italicum and its antioxidant, antimicrobial and cytotoxicity activities. Biotechnol Lett 41:899-914

51. Khashan KS, Sulaiman GM, Mahdi R (2017) Preparation of iron oxide nanoparticles-decorated carbon nanotube using laser ablation in liquid and their antimicrobial activity. Artif Cells Nanomed Biotech 45(8):1699-1709. https://doi.org/10.1080/21691401.2017.1282498

52. Foudaa MMG, El-Aassar MR, El Fawal GF, Hafez EE, Masry SHD (2015) K-carrageenan /Poly vinyl pyrollidone/polyethylene glycol/silver nanoparticles film for biomedical application. Int J Biol Macromol 74(3):179-184. https://doi.org/10.1016/j.jibiomac.2014.11.040

\section{Publisher's Note}

Springer Nature remains neutral with regard to jurisdictional claims in published maps and institutional affiliations. 